\title{
Aspirations and assumptions: a researcher's account of pupil involvement in school-based research
}

\section{Tessa L. Mearns, Do Coyle \& Rick de Graaff}

To cite this article: Tessa L. Mearns, Do Coyle \& Rick de Graaff (2014) Aspirations and assumptions: a researcher's account of pupil involvement in school-based research, International Journal of Research \& Method in Education, 37:4, 442-457, DOI: 10.1080/1743727X.2014.925440

To link to this article: http://dx.doi.org/10.1080/1743727X.2014.925440

\section{Published online: 05 Jun 2014.}

Submit your article to this journal $\sqsubset$

Џll Article views: 212

View related articles $\sqsubset$

View Crossmark data $\nearrow$ 


\title{
Aspirations and assumptions: a researcher's account of pupil involvement in school-based research
}

\author{
Tessa L. Mearns ${ }^{a *}$, Do Coyle ${ }^{a}$ and Rick de Graaff ${ }^{b}$ \\ ${ }^{a}$ School of Education, University of Aberdeen, Aberdeen, UK; ${ }^{b}$ Department of Languages, \\ Literature \& Communication, University of Utrecht, Utrecht, The Netherlands
}

(Received 6 September 2013; accepted 27 April 2014)

\begin{abstract}
This paper describes a research project conducted in collaboration with 10 'pupil co-researchers' (PCRs) and their classes in a secondary school in the Netherlands. The main research tools employed were online and face-to-face group discussions, in which PCRs contributed as consultants, co-designers and assistants. The research proved a learning experience for both the adults and the young people involved and led to the collection of insightful qualitative data. Working collaboratively with pupils, however, presented a number of challenges. Ethical issues such as consent, inclusion and the pressure placed on pupils, and logistical challenges such as the availability of time and resources, were particularly prominent. Perhaps the most valuable challenge, however, was the opportunity that this research presented to the adult researcher to reflect upon the role played by her own assumptions when working with young people.
\end{abstract}

Keywords: students as researchers; inclusive research; bilingual education

\section{Introduction}

Inclusive research with young people in schools has its ups and its downs, its advocates and its critics. This contribution gives a personal account of one example of inclusive research, which involved working together with pupils in the design and implementation of online and face-to-face discussions with their classmates. We subsequently used the qualitative data we obtained through these means to inform the design of a motivation questionnaire, which I administered to pupils at five different schools in a later, non-participatory phase of my doctoral research. The methods and processes of the collaborative phase of this research are described in some detail, as are some of the challenges encountered and the resulting considerations for future work of this kind.

We have chosen to write this account in the first person in order to reflect the personal nature of collaborative research. This project afforded an opportunity not only for data collection and for pupil learning, but also for researcher growth. The challenges involved in attempting to share the control over this research with a group of young people, and in balancing assumptions with their input, led to the investment of a significant amount of energy and personal reflection. We believe that this story is therefore better told from a subjective and possibly a more 'human' perspective. This paper is written largely with the singular 'I', not to belittle the contribution and considerable

\footnotetext{
*Corresponding author. Email: t.l.mearns@abdn.ac.uk
} 
support of my supervisors and co-authors, but to give an accurate representation of the research and my growth as a researcher. The pronoun 'we', unless otherwise stated, is used to refer to the first author and the pupil co-researchers (PCRs), rather than to a separate group of adult researchers.

\section{Rationales and advantages of participatory pupil research}

In the context of educational research in schools, it is 'the world which children know as insiders' (Alanen 2005, 31-45) that is investigated. It has been argued that 'insider' research, conducted from the social and cultural standpoint of the participant (Fielding 2004), provides access to data that may otherwise have been inaccessible. This may be because research participants are able to communicate more openly with their peers than with 'outsiders' (Atweh and Burton 1995; Schwartz 1988), because they can relate to and empathize better with participants of a similar age and background to themselves (Mitra 2001), or in the case of data collection methods such as participant observation, because the presence of a peer is less disruptive than that of an adult outsider (Leitch et al. 2007).

Further to being believed to produce more reliable or at least more practically applicable data (Bland and Atweh 2007; Mitra 2001), participatory research is also advocated for its benefits to the all-round ethos of an institution (MacBeath, Myers, and Demetriou 2001) and to the pupils and other stakeholders involved (Roberts and Nash 2009). Active involvement in research has been shown not only to give pupils the possibility to voice their opinion on topics relating to school life, but also to actively engage them as inciters of change and improvement within their school (Bland and Atweh 2007; e.g. Hollins, Gunter, and Thomson 2006; Kaplan and Howes 2004; Thomson and Gunter 2007).

My rationale for attempting participatory research in this study was based on a combination of motivations. I wished to engage participants actively and to gain access to genuine views and means of expression (Bragg 2007; Burke 2007). I also hoped that the pupils involved would benefit academically from first-hand exposure to real research practices, as in a larger scale study conducted by Bland and Atweh (2007). Furthermore, I was curious as to the practicalities and complexities of conducting this form of research. Reflections on the process of conducting this participatory pupil research are therefore addressed throughout, instead of in the final discussion of outcomes only.

\section{Cautionary observations on the value of pupil research}

In spite of the arguments in support of participatory research in schools, the literature provides warnings that such initiatives should be approached with caution and realism (Atweh and Burton 1995; Fielding 2004, 2007; Grundy 1998; Mannion 2007). According to Leitch et al., researching with pupils brings challenges that may be encountered at a number of different moments in the research process and that can only partially be predicted (Leitch et al. 2007). Furthermore, as Fielding argues, there are a number of ethical and epistemological issues that might lead us to question whether the approach can be considered valuable at all (Fielding 2007).

As Hadfield and Haw (2001) emphasize, it can be with the best of intentions that adult-led organizations conduct research and present findings which they believe to be representative of the needs and opinions of young people, or invite young people to offer an opinion on particular aspects of their lives through participatory research 
or pupil voice initiatives. They purport, however, that adult perspectives have a tendency to dominate even collaborative work with children and young people (CookSather 2007; Hadfield and Haw 2001), and as Fielding notes, children's voices can unknowingly be moulded to fit with an adult agenda (2004; Mannion 2007) or adult understanding (Mitra 2001). Thus pupils involved in research can be positioned as 'responder[s] to adult plans' (Hollins, Gunter, and Thomson 2006) rather than as stipulators of their own priorities and designers of their own approaches.

I aspired to involve pupils in research while remaining realistic about their level of responsibility. As the project was already part of a research proposal before pupils became involved, it was impossible to ask them to contribute to the earliest goalsetting and planning activities (Mallan, Singh, and Giardina 2010). For this reason, the PCRs were involved in a consultancy role and acted as ambassadors and assistants during data collection. While I hoped that involving pupils actively in the research would be beneficial both to the pupils and to the quality of the data collected, this project did, therefore, run the risk of becoming more adult-led than originally intended (Fielding 2004).

\section{Pupils studying pupil motivation: context and structure}

This pupil research formed a part of an ongoing study into the qualitative differences in the motivations of pupils in Dutch/English bilingual and Dutch-language ('regular') secondary schooling in the Netherlands.

Education in the Netherlands is divided into pre-university, general academic and pre-vocational streams from the beginning of secondary school at approximately age 12. Bilingual education, in which $30-50 \%$ of the curriculum is taught through a second language (usually English), is relatively well established in the Netherlands. At the time of writing, 123 of the country's 658 secondary schools offer bilingual programmes in one or more streams, usually parallel to a regular Dutch-language programme. Schools offering bilingual programmes in the pre-university stream number 118, whereas for the general academic and pre-vocational streams they number 49 for the former and 19 for the latter. The lower of these numbers increased between 2011 and 2013 from 31 and 3, respectively (Dienst Uitvoering Onderwijs 2013; Europees Platform 2013), indicating a possible move away from the approach's formerly 'elitist' connotations (Weenink 2005).

Acknowledging the lack of existing research and the host school's focus on improvement in this area, this study specifically targeted pupils in the first three years of general academic bilingual and regular Dutch-language education. This was also a convenient choice as, the research school also being the school in which I am an English teacher in the pre-university stream, I wished to avoid working with pupils whom I taught.

In the participatory phase of the project, we aimed to explore pupils' understandings of (language) learning motivation, its manifestations and its role in the learning process. This phase of the project sought to answer three research questions:

- Which areas of motivation and bilingual/regular education do the pupils view as worthy of discussion and how do these areas differ between the two groups?

- What are the pupils' perceptions of pupils in bilingual and regular education, and of their respective roles within the same school? 
- How does the active involvement of young people in research within their own school community affect the outcomes and processes of the research?

The largest proportion of the data was drawn from online discussions planned and facilitated by 10 PCRs and conducted on a specially designed website. These data were later supplemented with face-to-face group discussions. During the data analysis phase, I also referred to recorded conversations from meetings and training sessions with the PCRs and to my own research journal.

I later used the data relating to the first two research questions to inform the design of a survey, for use in the second phase of my Ph.D. research. These questions are, however, not answered in this paper, which focuses on the final research question, namely the experience and effect of conducting research collaboratively with young people.

\section{Research process}

\section{Election of pupil co-researchers}

The challenge of engaging a 'representative' group of pupils, while also considering the importance of 'fairness' to the other members of the class, has been highlighted as a complicated issue (e.g. Leitch et al. 2007). Having considered alternatives such as random selection (Leitch et al. 2007), informed selection by school staff (Sorrell and Sorrell 2005, cited by Burke 2007; Flutter and Rudduck 2006) and targeting specific groups of marginalized or 'more challenging' pupils (Bland and Atweh 2007; Hadfield and Haw 2001, 485-502; Roberts and Nash 2009), I decided to lay the responsibility for selecting the PCRs at the feet of the pupils themselves. I hoped that, in having the power to nominate a group of their peers whom they were comfortable with entrusting with the responsibility of representing their views and interests, pupils would feel more connected with and represented by the research (Pedder and McIntyre 2006; Thomson and Gunter 2007).

Five of the 10 PCRs came from a class of 25 second years aged between 12 and 14 in the general academic bilingual stream (Class A) and 5 from a class of 26 of the same age and level from the 'regular' Dutch-language stream (Class B). Selection took place by means of a ballot, in which each pupil nominated three peers and stated whether they wished to volunteer as a PCR. Before votes were cast, I explained the purposes, aims and ideals behind the research project, and what I was asking of the classes and the PCRs, and I offered the opportunity to ask questions and to opt in or out of participation in the project. Of the pupils who wished to volunteer, the five with the most votes were selected from each class.

For purposes of transparency and establishing positive communication (Leitch et al. 2007; Mallan, Singh, and Giardina 2010), selection of the PCRs was closely followed by an information meeting with their parents, in which I explained the project and gave parents the opportunity given to ask questions. I also issued parents of the PCRs with a consent letter.

\section{PCR training and preparation}

Work with the PCRs began with a training and preparation day. I organized and led the day, with support from the third author of this paper. My colleague and I explained 
the aims and objectives of the project, discussed and explored the concepts of 'research' and 'motivation', and introduced the PCRs to the concept of research ethics. During the preparation session, the PCRs divided themselves into pairs, each of which took on a specific task from the following list, which we had prepared together:

- develop consent forms and accompanying letters for classmates and their parents;

- begin designing the forum/website;

- divide the classes into subgroups for easier communication;

- select appropriate stimuli to be used for the first online discussion.

We also devised a timeline covering the academic year showing targets and key events, such as evaluation sessions.

I asked for pupils' consent to film our meetings as a record of discussions and to provide fuel for reflection. The PCRs enthusiastically took charge of most of the filming themselves.

\section{Online discussions: design and organization}

Although the website design was begun by the PCRs during the preparation session, time constraints, the difficulty of the task and the pupils' other commitments in school resulted in them handing responsibility for the website back to me. In consultation with the PCRs, I used the texts and ideas they had already provided to establish a website that I hoped would reflect their input. The PCRs examined and tested the finished website and gave feedback before it was made live, and wrote a set of instructions to use when assisting their classmates during the website launch.

Based on the literature on focus group research (e.g. Calder 1977) and on my own research goals, I assumed that each class should have its own website, and that discussions should be held in subgroups of between 8 and 12. The PCRs, however, felt strongly that there should be 1 website and 1 forum for all 51 pupils involved. They believed that a discussion with fewer people would not be as enjoyable and that 'nobody [would] want to do it because it's boring' (Yvette, ${ }^{1}$ Class B). While I explained my reasoning on the basis of research methodology, in the hope that they would change their minds, I was conscious of my commitment to respect the PCRs' views, and curious about whether their assertion was accurate. We agreed to begin by using a single forum and to re-evaluate this approach later.

Following Discussion 1, in which participation was largely limited to a small number of pupils, mostly from Class A, we wondered whether the large group size had had an adverse effect on participation. In the interests of ensuring that enough useful data be obtained (Bland and Atweh 2007), we therefore decided to divide the classes into smaller groups for subsequent discussions. We agreed that the smaller groups would include pupils from both classes rather than being entirely Dutch language or bilingual as I had originally assumed. The PCRs assigned their classmates to four subgroups across both classes, each with approximately 12 participants, including two or three PCRs. Both the PCRs and I were satisfied with this compromise, which reflected my need to ensure that the data were well balanced and the PCRs' conviction that their classmates were attracted to the project because it was an opportunity to work with pupils from a different class. This early hurdle might suggest that, while young people can offer added insight in research with their peers, trained adult researchers' 
knowledge and experience of research and methodology can be a necessary complement to this insight.

The PCRs preferred not to lead the website launch, but instead to assist in facilitating the session, with me in the leading role. Following my explanation and an opportunity for questions, each PCR was responsible for supporting a group of four or five classmates in registering for the forum, completing a short demographic questionnaire and accessing the discussion.

\section{Forum 'live' dates}

The discussion forum was made 'live' a total of three times throughout the school year. In Discussion 1, a simple question was posed ('Why would you want to learn a language?'), as formulated by the PCRs. For Discussion 2, inspired by pupil-led research conducted by Thomson and Gunter (2007), photographs formed the basis of the discussion. The images used as stimuli had been taken and selected by the PCRs and me, and were intended to reflect situations that might occur in the classroom. Each group was presented with a different photograph and two accompanying questions, one of which was the same for all groups, and one of which referred to the specific photograph presented, as in the example in Figure 1 (identities obscured).

Discussion 3 consisted of a comparison between one pair of short case scenarios per group, as in the example in Figure 2. The scenarios and questions were chosen and adapted by the PCRs from a selection of my suggestions.

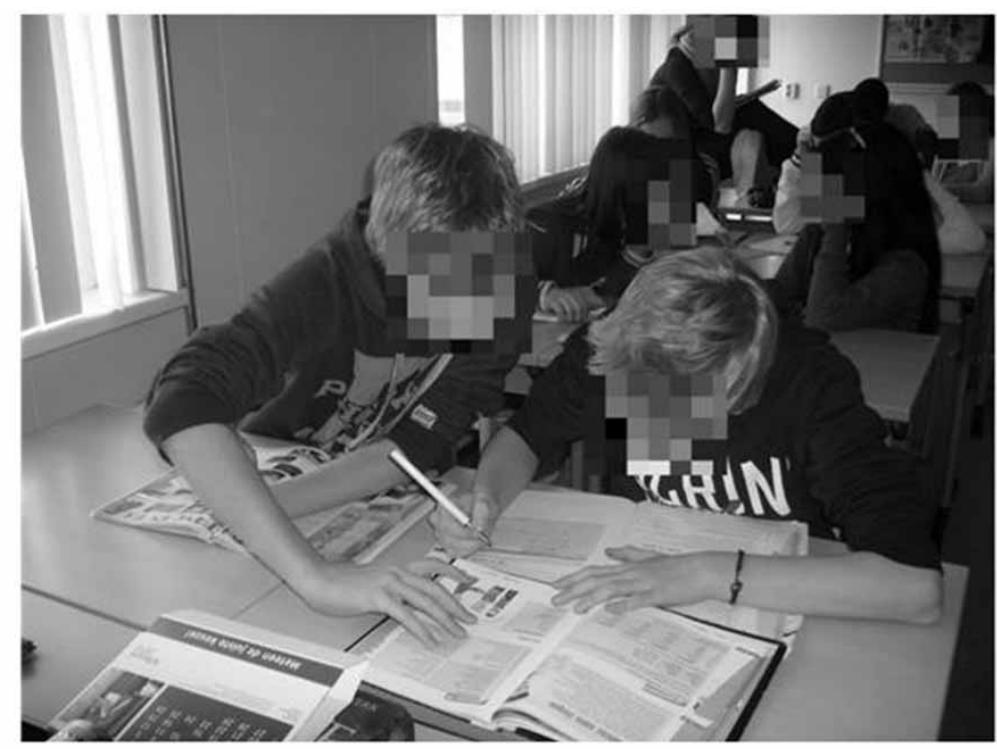

Qu.1: Do you think that these pupils are motivated? Why (not)?

Qu.2: Who is learning the most in this picture: the boys or the girls? Why do you think that?

Figure 1. Online Discussion 2, Group 1. 


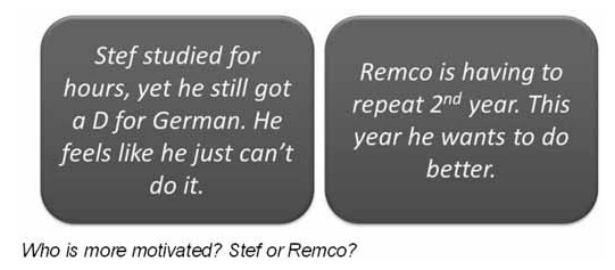

Figure 2. Online Discussion 3, Group 4.

In all three discussions, we encouraged pupils to respond to the stimulus and/or question presented, but also to each other's comments. The PCRs participated in the discussions along with their classmates, their contributions aimed at reanimating or re-focusing dwindling or drifting discussions, while I remained a silent observer.

\section{Reflection: running risks}

It is in areas such as the selection of stimuli that this project differed from more heavily pupil-led research such as those described elsewhere (e.g. Bland and Atweh 2007; Gunter and Thomson 2007; Kellett 2005). Rather than encouraging the PCRs to take full ownership of the research design and tools, I influenced them with my own suggestions, which were based on previous examples of participatory research. This limitation on the PCRs' autonomy is in part due to the nature of this study, which formed part of an existing project with goals and research questions already in place (Bland and Atweh 2007), but it might also reflect my own reluctance to relinquish full responsibility for the research (Bland and Atweh 2007) and fully 'translate' myself as a researcher (Cook-Sather 2007). In this sense, it could be argued that the pupils involved were indeed responding to adult plans, as warned by Hollins, Gunter, and Thomson (2006, 141-152) and by Fielding (2007, 301-310). Although the PCRs when asked did not express any dissatisfaction with their level of involvement, it might have been more desirable and engaging for them to work to their own agenda.

\section{Independence}

While Discussion 1 was opened during class, we had originally intended that the subsequent discussions would be conducted asynchronously, in pupils' own time. This proved ineffective, however, as the majority of pupils forgot about the discussions by the time they got home from school and had an opportunity to log on to the website. A similar issue was noted by Mallan, Singh, and Giardina (2010), who likewise reported having overestimated young people's enthusiasm for asynchronous, voluntary discussion on a researcher-led topic. After this issue had been noticed, I arranged for pupils to participate in the discussion synchronously during tutor lessons, with the support and encouragement of the PCRs and me. This proved to be a more successful approach, leading to the generation of a greater number of responses from a broader range of pupils.

\section{Live group discussions}

It has been remarked that 'researchers ... often fall back on tried and tested methods' (Mallan, Singh, and Giardina 2010, 255-272) rather than persisting with more experimental approaches to data collection. This project saw a similar preference among the 
young people involved. While I had expected pupils to be engaged with the idea of conducting research using online discussions, some of the pupils were unenthusiastic about this approach, and the PCRs from Class B suggested that we should abandon the website in favour of more 'conventional' discussions. Following the second round of online discussion, in which participation from Class B had been minimal, we decided to replace the final two online discussions with live, face-to-face group discussions using the same stimuli. As Class A was still enthusiastic about the online forum, we chose to complete the third online discussion before switching to the face-to-face approach for the fourth and final topic.

This late-stage transition to an alternative method of data collection, while instigated by the PCRs, came at the cost of the inclusiveness of this stage of the research. Due to time constraints, we were unable to prepare for the live discussions together, and I adopted a stronger position of 'leader' than I had originally intended. While the PCRs all participated in the discussions, their role at this stage was not significantly different to that of the other research participants. Furthermore, although the PCRs felt that the live discussions should be conducted in groups incorporating pupils from both classes, this proved logistically impossible to organize. We therefore conducted the discussions in separate groups of between 8 and 12 volunteers from each class.

\section{Data analysis, evaluation and reporting}

Mitra (2001) advocates inviting young people to be involved in research not only at the data collection stage, but also at the analysis stage. In keeping with my planning, most of the pupil collaboration in this project took place during the data collection stage. This was due to time constraints, as to train the pupils in and carry out detailed qualitative data analysis would have required more time than the PCRs either had or were prepared to contribute. I conducted the formal data analysis myself, but invited discussion from the PCRs regarding our findings following each round of discussion and, in particular, in our final evaluation meeting.

The purpose of the evaluation session was for the PCRs to discuss their feelings about the research process, to share experiences and to draw their own conclusions from the data. We did this through a discussion scaffolded by a version of de Bono's (2006) Plus-Minus-Interesting (PMI) tool, in which the PCRs were invited to share with each other what they had experienced positively, what they found less positive and what they felt they had learned from the experience. In the second half of the meeting, the PCRs worked in pairs to produce sections of a research report describing the motivation, methods, results and outcomes of the project, in both Dutch and English. We edited the final version of the report together to ensure that we all agreed on its structure, content and wording, and thus ended with a concrete product of our efforts.

\section{Outcomes}

The primary goal of this inclusive research work was the acquisition of data to inform the design of a survey intended for dissemination to a larger sample. Having transcribed and analysed the data, I used the conclusions drawn for their intended purpose.

My secondary goal, which is the focus of this paper, was to gain first-hand experience and understanding of what inclusive research with young people involves. In this regard, some outcomes were positive, while others further highlighted the challenging 
nature of inclusive research. Reflections on these successes and challenges are presented below.

\section{Successes: learning and growth}

I consider the collaborative approach taken in this research to have been in many respects a success. In addition to the data obtained for the subsequent phase of my research, working together on research provided both the pupils and me with an opportunity to gain new skills and experience, which could lay the groundwork for more collaborative research projects in the future.

\section{Pupil learning}

In some participatory research projects, pupil researchers are quoted as mentioning explicitly that they feel they have learned about what it means to conduct research (e.g. Atweh and Burton 1995). Beyond one remark that 'Research takes a lot of time' (Ana, Class B PCR, Evaluation meeting), however, the PCRs in this project did not choose to comment on this during our PMI evaluation session. In spite of this, the PCRs' level of engagement in and contribution to the research suggested that their understanding of what it means to carry out research was enhanced during their involvement in the project. Through the training session and research activities, they learned about the importance of ethics and reliability, and they relayed some of this learning to their peers through the consent letters and the introductory activities with their classes, during the online and live discussions, and in the production of the research report. They experienced different ways of recording data, such as notetaking, filming and audio recording, as well as online methods. Furthermore, they were responsible for the production of a traditionally structured research report and developed relationships with two academic researchers, as a first glance into the academic world (Bragg 2007).

Teaching pupils about motivation was not an explicit goal of the research, but nevertheless at the end of their collaboration, the PCRs also appeared to have developed deeper understanding of what it means to be motivated, as can be seen from the following (unprompted) conversation during our final meeting:

Sam: There are lots of different sorts of motivation.

Me: $\quad[\ldots]$ And what kinds of motivation have you noticed?

Sam: Well, you might want to pass the year, or you might want to do something for your parents' sake or whatever...

Me: $[\ldots]$ Are there any other kinds of motivation?

Yvette: For yourself.

(Evaluation meeting, 16 May 2012)

This contrasts with conversations from the beginning of the project, when the examples of motivational factors identified by the PCRs were all related either to instrumental goals or to pleasing others. At the end of the year, as the above exchange suggests, they appeared to be more aware of the presence of different types of motivation in different contexts, including intrinsic motivation that is driven by internal rather than instrumental factors (Deci and Ryan 1985, 2002). 


\section{Researcher learning}

Cook-Sather (2007) explores the potential for collaborative work with children and young people for researcher development. As Mitra (2001) highlights, approaches intended to allow young people to voice their views can be limited by adults' inability to accurately interpret what young people say. Her suggestion is that allowing young people to analyse and interpret their own data will avoid problems with 'mistranslation'. Cook-Sather, on the other hand, develops the concept of 'translation' in the sense of the researcher adjusting her own way of being in order to better relate to and understand young research participants, meeting them in their experience rather than attempting to interpret it from an adult perspective. This process of reframing one's own role as a researcher, she purports, is preferable to the more common practices of either expecting young people to 'translate' themselves into forms more accessible to adults (Cook-Sather 2007).

In my case, the task of translating myself in Cook-Sather's (2007) sense of the word involved meeting the PCRs in their experience of the research, yet also striking a balance between relinquishing control and remaining conscious of the differences between myself and my young co-researchers. As I gathered from the difference of opinion regarding group size, respecting young people's views and perspectives may not always mean ignoring my own judgement as a more experienced researcher, but could be an indication that more attention needs to be to training young co-researchers in research methods. In this sense, finding the balance between supporting a research project and directing it can present a further level of challenge and complexity.

In spite of the complexities of 'translation' in this project, however, direct communication with the pupil researchers, and observation of their interactions and their reaction to research activities led me to develop new insights and, more markedly, to lay aside old assumptions, for example, with regard to young people's eagerness to communicate in an online setting (Mallan, Singh, and Giardina 2010) or indeed to be involved at all (Bragg 2007). As the title of this paper suggests and as can be understood from the following section, it was perhaps this challenging of assumptions and increased awareness of the complexities of translation that were my areas of greatest growth and gain for me, as a researcher and as an educator, in carrying out this research.

\section{Challenges and solutions}

As the literature suggests, research conducted alongside pupils in schools can present as many challenges as it does advantages (Bragg 2007; Burke 2007; Fielding 2004, 2007, 301-310; Leitch et al. 2007; Mallan, Singh, and Giardina 2010; Mannion 2007). Particular challenges encountered in this project involved striving to remain within ethical boundaries, dealing with the limited time and resources available for working with the PCRs and their classes, and attempting to ensure that the pupils' contribution to the research was enjoyable, effective and meaningful (Bland and Atweh 2007; Gunter and Thomson 2007; Hadfield and Haw 2001).

\section{Ethical challenges}

The ethical hurdles I encountered related largely to the organization and practical implementation of the project, and to the fair treatment of the PCRs and their peers. In particular, issues arose regarding interference with schoolwork and inclusion. 
Effect on schoolwork. In total, the PCRs and I had approximately 25 hours of contact time throughout the school year, including training and preparation, research activities and evaluation time. One of the first concerns raised by the school, the pupils and the parents on the introduction of the project was the amount of pressure participation as a PCR might create on top of an already heavy study load. I had anticipated this and attempted to address this concern from the outset.

The PCRs and I consulted carefully to arrange meeting times to avoid conflict with lessons, busy periods at school, after-school tutoring and extra-curricular activities (Mallan, Singh, and Giardina 2010). Meetings that did take place during school time were planned for during activity weeks, tutor lessons (in consultation with the tutors) or lessons volunteered by subject-teachers as being 'missable' for the pupils involved. I made an effort to allow space for activities such as planning and preparation of materials to be completed during meeting times so that the PCRs did not have the extra burden of having to work for the project at home. While this ensured that the majority of tasks were carried out and completed rather than being forgotten, it did contribute to the shortage of time.

Inclusion and representativeness. While I took measures to ensure that the selection of pupil researchers was carried out fairly, the representativeness of the PCRs was nevertheless questionable. Pupils were given the opportunity to vote for others and to nominate themselves as volunteers. While this appears to be a democratic approach, however, it does carry the risk that pupils will choose only the most vocal or most popular members of their group (Hadfield and Haw 2001). According to Fielding (2004), the shyer, quieter or less confident pupils, those less popular with their peers or those frequently absent can be overlooked, yet these might be the voices that it is most valuable to hear.

This issue of representativeness of the PCRs was particularly apparent in Class B. For example, it became apparent during a live discussion that some members of Class B felt uncomfortable about interacting with Class A. This was how one of the non-PCR participants explained her and her friend's change of heart about participating in the live discussion:

The last time we thought that there was another class here too and I don't think she wants that, and this time she knew it wasn't like that. (Live discussion with Class B, 22 March 2012)

This was a conflict which had not been felt by the PCRs, who had actually requested that the classes be brought together for all discussions. It is possible that Class B's rejection of the online discussions was related to the same reluctance to communicate with Class A as is apparent in the above comment. The five pupils elected to represent Class $\mathrm{B}$ in the research were among the most overtly confident in the class, and embraced the opportunity for collaboration and social contact with peers from another class, but this does not mean to say that their classmates felt the same way. This reflects CookSather's (2007) warning that young people's views should not be generalized simply on the basis of their age or background.

\section{Logistical challenges}

Limitations on pupil involvement. The primary goals for the broader research project already being in place, it was not possible to hand over as much responsibility to 
pupils as has been the case in some other pupil research projects (Raymond 2001). For example, I consulted the PCRs regarding the exact focus and wording of our main research question, but the general focus of the study had already been put in place before they became involved. A similar issue was encountered by Mallan, Singh, and Giardina (2010), whose funding application required them to design the research before their participants had been selected.

While practical constraints made it difficult for the research to be emancipatory or empowering in the sense of pupils adopting a high level of control over its goals and implementation, I did prioritize establishing a climate of trust between us (Bland and Atweh 2007; Grundy 1998; Pedder and McIntyre 2006; Roberts and Nash 2009). At the beginning of the project, I assured the pupils that I would listen to them and that their views would be incorporated into the project wherever possible, while remaining careful not to promise them more control over the project than I was able (or willing) to give them. I strove to honour this commitment even when, as in the decision to combine the classes for the purpose of the online discussions, the PCRs' views or suggestions contradicted what I considered to be my informed judgement. At this point, I hoped that evidence from previous studies (e.g. Bland and Atweh 2007) that data obtained through participatory research can be more valuable due to 'insider' knowledge would be reflected in our data and therefore attempted to lay aside my own assumptions regarding group size.

Cooperation, enthusiasm and engagement. While some researchers have found that pupils involved in research projects embrace the opportunity to have their voices heard and to work autonomously (e.g. Bragg 2007; Coyle 2011; Roberts and Nash 2009), others have found young participants more enthusiastic about 'belonging' to a project than about actually participating in it (Mallan, Singh, and Giardina 2010). In her consideration of the politics of pupil participation, Bragg (2007, 343-358) observes that school leaders display an assumption of a pre-existing 'will to participate' and to be involved and consulted among pupils. Mallan, Singh, and Giardina (2010) reflect that this is one of the assumptions that can easily be made in relation to young people, but which is not always experienced in practice as accurate. In this project, I observed this distinction on both individual and group levels, one of the classes displaying enthusiasm and engagement throughout the project and the other appearing relatively disinterested from the beginning.

Response to online method. In a similar attitude to Mallan, Singh, and Giardina (2010), I had based my decision to carry out data collection online on the assumption that younger generations will find Internet-based activities accessible and relevant to their needs and experiences. Indeed, a potential failing of participatory research projects has been argued to be that data are often collected from within adult-dominated environments, rather than in, for example, the networked environments that young people in the twenty-first century are more likely to inhabit (Cook-Sather 2002, 313; Mallan, Singh, and Giardina 2010).

It is interesting to note, however, that Kellett's (2005) major work on child-led research does not involve 'innovative' methods of data collection, but focuses on training children and young people to use more traditional methods (Wiles et al. 2013). Furthermore, as Cole (2009) observes in her account of an attempt to use Wikis to support learning, engagement in interactive online content is for many people a 
passive undertaking, and barriers of time-pressure, self-confidence and technical accessibility can prevent participants from taking on a more active role. Moreover, both Cole (2009) and Mallan, Singh, and Giardina (2010) highlight the risk of assuming that younger generations possess inherent knowledge and understanding of online media, and that they experience online interaction as 'fun', when this is not always the case. Indeed, as Oblinger and Oblinger (2005) emphasize, younger generations place great value on face-to-face social interaction, in spite of the prominence of online environments in their everyday lives. This was reflected in the views expressed by the PCRs and their classmates: feedback from the PCRs halfway through our project demonstrated that many of the participants were not comfortable with the online discussions and preferred working with methods more familiar to them.

A further possibility is that the online tool did not relate to their existing online lives. In employing digital methods for data collection I had hoped that I would be meeting pupils in an environment that they viewed as their own. I did not understand until later that a digital space selected by an external adult was no more 'theirs' than a physical one would have been (Castells 1996; Cole 2009; Mallan, Singh, and Giardina 2010). Early conversations with the PCRs suggested that they would find it more accessible and more appealing to participate in discussions if they were to take place on an existing social networking site, such as Twitter or Facebook, rather than on a custom-made website, but I had rejected this possibility on the basis of security and inclusion. Perhaps this might have been a more successful approach had I laid aside my assumptions and listened more attentively to the PCRs.

\section{Conclusions and recommendations}

Before entering into this project, I envisaged an atmosphere of trust, collegiality and cooperation, in which I would work together with pupils in a common quest for knowledge, understanding and empathy. I imagined that we would learn from one another and work with and for one another in order to achieve our shared objectives. Considering the more positive literature on participatory research (e.g. Hollins, Gunter, and Thomson 2006), it appears that this can be a realistic goal. Alongside those reports, however, there is an array of accounts of experiences such as this one, in which the assumptions and aspirations of the researcher have led to successes being counterbalanced with disappointments.

The partnership between researchers and 'researched' in this research project appeared to be valued by the pupil researchers involved, who showed evidence of having learned from the experience. Their growth and development were apparent even when not voiced explicitly, for example, in their mature attitude to data collection and handling, their ability to work together and take on leadership roles and their production of a research report. For me, this study afforded the opportunity to learn firsthand from a group of young 'expert witnesses' (Roberts and Nash 2009, 174-187) about their experiences of research and of school, and to explore my own identity and means of communicating as a researcher.

The data obtained through this qualitative phase of the study were central to the development of the questionnaire used for larger scale data collection in the second phase of the research, which, aside from the meta-goal of exploring an alternative to researcher-centred research, was the main purpose of this phase of the study.

Alongside the successes, this style of working brought with it a number of trials. Careful planning allowed us to avoid many of the difficulties explored in existing 
literature, yet we encountered an equally significant number of challenges that I had not anticipated. This was in part due to my own assumptions as a researcher and the fact that I did not fully 'translate' myself as recommended by Cook-Sather (2007, 389403), and indeed also due to precisely the 'careful planning' just referred to. It was perhaps my own determination to prevent our encountering the same problems documented in existing literature (e.g. Leitch et al. 2007) that led to a degree of inflexibility and therefore limited pupils' contribution to the research, just as Hadfield and Haw (2001) warn may occur.

Due to time and logistical constraints, pupils played a less prominent role in the research than I had intended, and I took on more responsibilities than originally planned. This gave rise to questions regarding the value of involving pupil researchers, and to my questioning of my own 'readiness' to relinquish enough control to make the pupils' participation meaningful. The unpopularity of the online aspect of the research with one of the two classes in particular, while unexpected, could be viewed as revealing of the different natures of the two classes involved in the study, and therefore provided useful data in itself.

Unburdened by the constraints of being part of a larger pre-defined project, I hope that future studies might allow for further, in-depth involvement of pupil researchers, who might be given the freedom to choose their own research focus and methods, with adults involved at a greater distance to offer advice, supervision or logistical support, as in Roberts and Nash (2009). This would, however, require more time and resources for training, planning, implementing the research and analysing data, as has been seen in some other pupil research projects (e.g. Bland and Atweh 2007; Fielding and Bragg 2003). While engagement in inclusive research brings a number of benefits, it nevertheless involves the investment of a great deal of time, organization and reflection if the process and the outcomes are to be valuable to the pupils, the school and the wider (research) community.

As Leitch et al. (2007) maintain, every pupil research project has its idiosyncrasies and carries with it a unique set of challenges and successes. Through publishing not only the findings of pupil research, but also observations and considerations on the processes involved and trials encountered, I sincerely hope that this research will contribute to the growing body of documentation on pupil research, which can be used by future researchers for both academic and practical purposes (Mallan, Singh, and Giardina 2010).

\section{Acknowledgements}

I wish to thank sincerely the PCRs and their classmates who helped me on this journey of discovery, and whose contribution continues to be the inspiration for my research. Thanks are also due to the school in which this research was carried out.

\section{Note}

1. No real names have been used.

\section{References}

Alanen, L. 2005. "Women's Studies/Childhood Studies. Parallels, Links and Perspectives.” In Children Taken Seriously: In Theory, Policy and Practice, edited by J. Mason and T. Fattore, 31-45. London: Jessica Kingsley. 
Atweh, B., and L. Burton. 1995. "Students as Researchers: Rationale and Critique." British Educational Research Journal 21 (5): 561-575.

Bland, D., and B. Atweh. 2007. "Students as Researchers: Engaging Students' Voices in PAR." Educational Action Research 15 (3): 337-349.

de Bono, E. 2006. De Bono's Thinking Course. Harlow: Pearson Education.

Bragg, S. 2007. “'Student Voice' and Governmentality: The Production of Enterprising Subjects?" Discourse: Studies in the Cultural Politics of Education 28 (3): 343-358. doi:10.1080/01596300701458905. http://dx.doi.org/10.1080/01596300701458905

Burke, C. 2007. "The View of the Child: Releasing 'Visual Voices' in the Design of Learning Environments." Discourse: Studies in the Cultural Politics of Education 28 (3): 359-372. doi:10.1080/01596300701458947. http://dx.doi.org/10.1080/01596300701458947

Calder, B. J. 1977. "Focus Groups and the Nature of Qualitative Marketing Research." Journal of Marketing Research 14 (3): 353-364.

Castells, M. 1996. The Rise of the Network Society. Oxford: Blackwell.

Cole, M. 2009. "Using Wiki Technology to Support Student Engagement: Lessons from the Trenches." Computers \& Education 52 (1): 141-146.

Cook-Sather, A. 2002. "Authorizing Students' Perspectives: Towards Trust, Dialogue, and Change in Education." Educational Researcher 31 (4): 3-14.

Cook-Sather, A. 2007. "Resisting the Impositional Potential of Student Voice Work: Lessons for Liberatory Educational Research from Poststructuralist Feminist Critiques of Critical Pedagogy." Discourse: Studies in the Cultural Politics of Education 28 (3): 389-403. doi:10.1080/01596300701458962. http://dx.doi.org/10.1080/01596300701458962

Coyle, D. 2011. Investigating Student Gains: Content and Language Integrated Learning: Italic Research Final Report for Esmée Fairbairn Foundation. Aberdeen: University of Aberdeen.

Deci, E. L., and R. M. Ryan. 1985. Intrinsic Motivation and Self-determination in Human Behavior. New York: Plenum.

Deci, E. L., and R. M. Ryan, eds. 2002. Handbook of Self-determination Research. Rochester, NY: The University of Rochester Press.

Dienst Uitvoering Onderwijs. 2013. "Adressen voortgezet onderwijs.” Ministerie van Onderwijs, Cultuur en Wetenschap. Last modified December 2, 2013. Accessed January 2, 2014. http:// www.duo.nl/organisatie/open_onderwijsdata/databestanden/vo/adressen/default.asp

Europees Platform. 2013. "Tto scholen.” Europees Platform. Accessed May 14, 2014. http:// www.europeesplatform.nl/tto/scholen/

Fielding, M. 2004. "Transformative Approaches to Student Voice: Theoretical Underpinnings, Recalcitrant Realities.” British Educational Research Journal 30 (2): 295-311.

Fielding, M. 2007. "Beyond 'Voice': New Roles, Relations, and Contexts in Researching with Young People." Discourse: Studies in the Cultural Politics of Education 28 (3): 301-310. doi:10.1080/01596300701458780. http://dx.doi.org/10.1080/01596300701458780

Fielding, M., and S. Bragg. 2003. Students as Researchers: Making a Difference. Cambridge: Pearson.

Flutter, J., and J. Rudduck. 2006. Student Voice and the Architecture of Change: Mapping the Territory (Report to the Research Committee). Cambridge: University of Cambridge.

Grundy, S. 1998. "Research Partnerships: Principles and Possibilities." In Action Research in Practice: Partnership for Social Justice, edited by B. Atweh, 37-46. London: Routledge.

Gunter, H., and P. Thomson. 2007. "But, Where Are the Children?" Management in Education 21 (1): $23-28$.

Hadfield, M., and K. Haw. 2001. “'Voice', Young People and Action Research.” Educational Action Research 9 (3): 485-502.

Hollins, K., H. Gunter, and P. Thomson. 2006. "Living Improvement: A Case Study of a Secondary School in England." Improving Schools 9 (3): 141-152.

Kaplan, I., and A. Howes. 2004. “'Seeing Through Different Eyes': Exploring the Value of Participative Research Using Images in Schools." Cambridge Journal of Education 34 (2): $143-155$.

Kellett, M. 2005. How to Develop Children as Researchers: A Step by Step Guide to Teaching the Research Process. London: Sage.

Leitch, R., J. Gardner, S. Mitchell, L. Lundy, O. Odena, D. Galanouli, and P. Clough. 2007. "Consulting Pupils in Assessment for Learning Classrooms: The Twists and Turns of Working with Students as Co-researchers." Educational Action Research 15 (3): 459-478. 
MacBeath, J., K. Myers, and H. Demetriou. 2001. "Supporting Teachers in Consulting Pupils about Aspects of Teaching and Learning, and Evaluating Impact." FORUM 43 (2): 78-82.

Mallan, K. M., P. Singh, and N. Giardina. 2010. "The Challenges of Participatory Research with 'Tech-savvy' Youth." Journal of Youth Studies 13 (2): 255-272. doi:10.1080/ 13676260903295059. http://dx.doi.org/10.1080/13676260903295059

Mannion, G. 2007. "Going Spatial, Going Relational: Why 'Listening to Children' and Children's Participation Needs Reframing." Discourse: Studies in the Cultural Politics of Education 28 (3): 405-420. doi:10.1080/01596300701458970. http://dx.doi.org/10.1080/ 01596300701458970

Mitra, D. 2001. "Opening the Floodgates: Giving Students a Voice in School Reform." FORUM 43 (2): $91-94$.

Oblinger, D., and Oblinger, J. 2005. "Is It Age or IT: First Steps Toward Understanding the Net Generation." Educause. Accessed January 2, 2014. http://www.educause.edu/research-andpublications/books/educating-net-generation/it-age-or-it-first-steps-toward-understandingnet-generation

Pedder, D., and D. McIntyre. 2006. "Pupil Consultation: The Importance of Social Capital." Educational Review 58 (2): 145-157.

Raymond, L. 2001. "Student Involvement in School Improvement: From Data Source to Significant Voice." FORUM 43 (2): 58-61.

Roberts, A., and J. Nash. 2009. "Enabling Students to Participate in School Improvement Through a Students as Researchers Programme." Improving Schools 12 (2): 174-187.

Schwartz, J. 1988. "The Drudgery and the Discovery: Students as Research Partners.” English Journal 77 (2): 37-40.

Sorrell, J., and F. Sorrell, eds. 2005. The Sorrell Foundation. Joinedupdesignforschools. London: Merrell.

Thomson, P., and H. Gunter. 2007. "The Methodology of Students-as-Researchers: Valuing and Using Experience and Expertise to Develop Methods." Discourse: Studies in the Cultural Politics of Education 28 (3): 327-342.

Weenink, D. 2005. "Upper Middle-Class Resources of Power in the Education Arena. Dutch Elite Schools in an Age of Globalization." Doctoral thesis, University of Amsterdam, Amsterdam.

Wiles, R., A. Bengry-Howell, G. Crow, and M. Nind. 2013. "But Is It Innovation?: The Development of Novel Methodological Approaches in Qualitative Research." Methodological Innovations Online 8 (3): 18-33. 